\title{
Counting Possible Configurations
}

\author{
Manfred Krifka
}

\begin{abstract}
It is often assumed that a requirement for counting objects is that they do not overlap. However, this condition can be violated. The paper deals, specifically, with counting objects that consist of parts, that is, with configurations. One example is outfit as a configuration of articles of clothing; notice that one article of clothing may be part of different outfits. The article develops an analysis of such configurational entities as individual concepts. It investigates the interaction of noun phrases based on such nouns with modal operators and in collective and cumulative interpretations.
\end{abstract}

Keywords Counting $\cdot$ Configurational objects $\cdot$ Individual concepts $\cdot$ Modal operators

\section{Introduction}

One of the conditions for counting is that the atoms of counting should not overlap (cf. e.g. Rothstein 2010; Landman 2016). The reason for this is obvious: In cases in which the atoms of a count noun are not settled, only a non-overlap condition will provide us with a counting function that yields a unique number. For example, when asked how many body parts a person has, it would be misleading to count the left

The analysis presented in this article was first presented as "Counting Configurations" at Sinn und Bedeutung 13 in 2009 in Stuttgart, and published in the proceedings Arndt Riester and Torgrim Solstad (eds.), pp. 309-324. University Stuttgart: SinSpeC; it is currently unavailable there. The present article is substantially extended. I thank the audiences at that conference, and at the conference Cognitive Structures in September 2016 at the University of Düsseldorf. In particular, thanks to Regine Eckardt, Ilaria Frana, Hans-Martin Gärtner, Andreas Haida, Stefan Hinterwimmer, Sophie Repp, and Magdalena Kaufmann for helpful comments, and to Sebastian Löbner especially for comments on the proper analysis of the main example of this article, outfit. Of course, for any problems of the theory and its exposition, I am solely responsible.

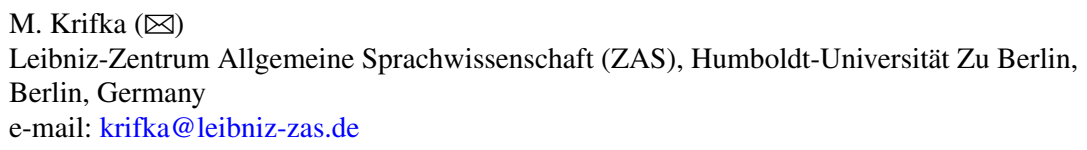


arm, the left hand, and the five fingers of the left hand as distinct body parts, ending up with seven body parts on the left upper limb. Similarly, when asked how many sequences of letters there are in the set $\{$ abcde, hijkl, mnopq $\}$, the answer 3 will be appropriate, but not 39 , the number of sequences of two or more letters contained in these three maximal sequences.

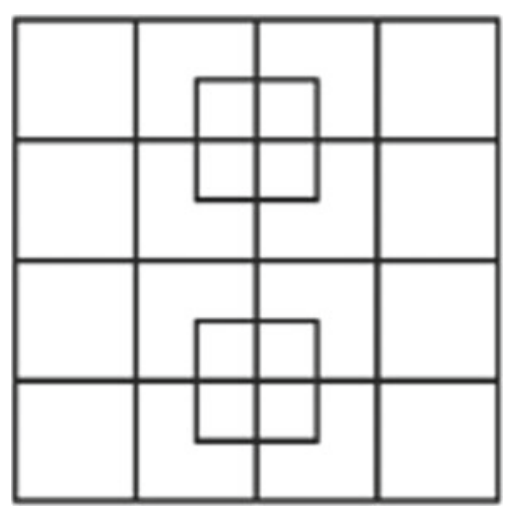

However, there are contexts in which the disjointment requirement can be loosened up. There are riddles like How many squares are in this figure? which can perfectly well be answered by considering overlapping squares (in the picture to the right, this would result in 40 squares $^{1}$ ). Counting overlapping entities may also be necessary in contexts that clearly are not riddles. For example, one study found that there are 5815 craters on the moon with a diameter $\geq 20 \mathrm{~km}$, many of them overlapping. ${ }^{2}$ Or we might want to know how many stories are actually contained in the Arabian Nights, which famously contains stories nested in stories-e.g., there is a story contained in a story contained in a story contained in a story contained in a story. ${ }^{3}$ Even the counting of sequences might give rise to second thoughts, as the following entry in the discussion board for the board game Sequence shows ${ }^{4}$ :

(1) Just bought this game today and was playing with my young son. In the second game, he managed to construct a 6 in a row sequence. Now, this could be considered as being 2 overlapping 5 chip sequences. The rules are fairly sparse, but the strict definition is a sequence is "a connected series of five of the same colour marker chip in a straight line. If the definition was modified to " .. five or more .." then it would be clearer that you cannot overlap sequences in the same direction.

\footnotetext{
${ }^{1} \mathrm{Cf}$. http://www.puzzlesandriddles.com/PerceptualPuzzle06.html.

${ }^{2}$ https://cosmoquest.org/x/blog/2012/02/how-many-craters-are-on-the-moon/.

${ }^{3}$ E.g. the e.g. the Tale of the Husband and the Parrot, see https://en.wikipedia.org/wiki/List_of_stor ies_within_One_Thousand_and_One_Nights.

${ }^{4}$ https://boardgamegeek.com/thread/587189/why-dont-you-count-6-row-two-sets-5-sequences.
} 
In addition to entities that overlap in a given world, there are entities that arguably show overlap only in other worlds than the real world. Consider the following example ${ }^{5}$ :

(2) You have 3 shirts and 4 pairs of pants. How many different outfits can you make? [...] You get twelve outfits. Not counting if a dude makes an outfit without a shirt, or a crazy person without pants.

Assume we have three shirts $\mathrm{s}_{1}, \mathrm{~s}_{2}, \mathrm{~s}_{3}$ and four pairs of pants $\mathrm{p}_{1}, \mathrm{p}_{2}, \mathrm{p}_{3}, \mathrm{p}_{4}$, we can form twelve pairs of a shirt and a pair of pants, such as $\left\langle\mathrm{s}_{1}, \mathrm{p}_{1}\right\rangle,\left\langle\mathrm{s}_{2}, \mathrm{p}_{2}\right\rangle,\left\langle\mathrm{s}_{2}, \mathrm{p}_{1}\right\rangle$ and so on-twelve possible combinations altogether. Notice that the question here is not, How many outfits are these? The answer to that question would probably be three, if we count as an outfit a pair of a shirt and a pair of pants. That shirt $\mathrm{s}_{1}$ makes an outfit with $\mathrm{p}_{1}$ and also with $\mathrm{p}_{2}$ does not count, because we could not dress two persons at the same time with it. The question, rather, is How many outfits can you $\underline{m a k e}$ ?, where the modal can makes a crucial contribution. It requires that we look at different circumstances, where in some $\left\langle\mathrm{s}_{1}, \mathrm{p}_{1}\right\rangle$ makes an outfit, in others $\left\langle\mathrm{s}_{1}, \mathrm{p}_{2}\right\rangle$ makes an outfit.

Once one is aware of such cases, it is not difficult to find more, or to construct convincing examples at will ${ }^{6,7,8}$ :

(3) [Description of a tangram set.] With just seven simple pieces, you can make dozens of amazing shapes.

(4) [Description of fischertechnik crane construction kit:] 100 Bauteile ermöglichen den Bau dreier unterschiedlicher, einfacher Kräne.

'With 100 construction parts enable one to build three different, simple cranes.'

(5) [Description of Scrabble Word Builder:] We typed in the letters

C, D, P, N, Y, E, A, and U and the Word Builder provided dozens and dozens of words that could be created with those letters.

\footnotetext{
5 answers.yahoo.com/question/index?qid=20080723031442AAYcny3. The text continues: "Now let's say you throw in three different pairs of socks...then you'd have 3 shirts times 4 pairs of pants times 3 pairs of socks for 36 . It can get crazy the more options you throw in there."

${ }^{6}$ www.amazon.com/Think-Fun-4985-Tangram/dp/B000BXHP04.

${ }^{7}$ spielwaren.1index.de/Fischertechnik@Cranes@Fischertechnik@Basic.19673.WOB000000 01.13.

${ }^{8}$ www.education-world.com/a_lesson/dailylp/dailylp/dailylp099.shtml.
} 
Our main concern here is in the fact that even though these sentences talk about twelve outfits, dozens of tangram shapes, three cranes, and dozens and dozens of words, they do not imply that at any one possible world or point in time, dozens of shapes, twelve outfits, three cranes, or dozens of word tokens constructed with a set of eight scrabble pieces co-exist. Nevertheless, these sentences are true. The numeral constructions like twelve outfits appear to count things that exist across the different possible worlds or times referred to by the modal or temporal operators of the sentences. Notice that each of the sentences contains a modal marker, here underlined.

Perhaps this might not appear so remarkable for our examples if tangram shape, crane, or word refer to types (or kinds), which presumably have a more abstract way of existence anyway. But the examples can easily be read to refer to the concrete tangram pieces, construction parts, and scrabble letters in front of our eyes. And (2) does not lend itself to a type reading; the shirts and pants that are mixed and matched may well be unique.

\section{The Problem with Configurations}

I will assume that words like outifit, tangram figure, but also crane and word, apply to "configurations". They refer to entities that consist of well-individuated parts that come together at certain worlds and times to form a certain configuration or to serve a purpose, but may be taken apart and be reconfigured at other indices. I take this to mean that words like outfit do not refer to regular individuals, type e, as this would not account for the fact that their parts are used to make up another individual at other indices.

To make our discussion more concrete, consider the following example, a simplified variant of (2).

(6) It is possible to make four outfits with these two shirts and two pants.

We assume an interpretation format with explicit quantification over indices for worlds or times (including time intervals), and with entities that can be combined to form sum entities. I use $i, i^{\prime}$ etc. as variables over indices (type $s$ ), and $u, u^{\prime}$ etc. as variables over entities (type e), and $\mathrm{I}$ write $\mathrm{u} \sqcup \mathrm{u}^{\prime}$ for the sum (join) of $\mathrm{u}$ and $\mathrm{u}^{\prime}$, which is also of type e (cf. Link 1983 for the material join operation). Entities like outfits, tangram figures, cranes, and words are complex, as they typically consist of parts that are recognizable entities themselves. For example, a fischertechnik toy crane consists of various plastic pieces that are stuck together to resemble a crane, a tangram figure consists of the seven tangram pieces arranged in a way that iconically depicts another entity, an orthographic word consists of letters arranged in a linear sequence, and an outfit consists of articles of clothing that dress a person in a culturally acceptable way. The noun outfit comes with an additional complexity, as it is also a functional term (Löbner 2011); we speak of the outfit of Mary at a time $t$ as the clothes that 
Mary wore at t. ${ }^{9}$ However, in examples like (2) it has a non-functional interpretation, and other nominals like crane and tangram figure that show the same configurational interpretation do not have a functional reading at all. In the non-functional reading of outfit, the person that is wearing the outfit is implicit, and the meaning of outfit could be given as follows:

(7) $\llbracket$ outfit $\rrbracket=\lambda \mathrm{i} \lambda \mathrm{u}[\mathrm{u}$ consists of articles of clothing worn by a person in $\mathrm{i}$, where the articles and their arrangement in i satisfy the accepted dress codes in i]

According to this approach, the intension of outfit maps each index $i$ to the set of entities $u$ that consists of articles of clothes worn by a person at $i$ in a way that follows the dress code at $i$ (the latter provides for the facts like that a shirt and a pair of pants would not count as a complete outfit at an index with more formal standards). ${ }^{10}$

There is an implicit assumption in configurational objects like outfits that is important to be made explicit here: At any one index, an article of clothing can be used to dress only one person. We normally do not count two shirts and one pair of pants as two outfits, even if the pants are very large so that one slender person squeezes into each pant leg, and is additionally dressed by a shirt.

The numeral four can be represented in various ways. Let us assume here the standard Generalized Quantifier analysis, where $\mathrm{P}$ is a variable over properties, type set, and \# is a function that, when applied to a function of entities to truth values, type et, yields the number of entities that are mapped to the value 1, truth. In the Generalized Quantifier interpretation of numerals this is commonly assumed to be at least 4, in contrast to the quantifier exactly four (cf. Barwise and Cooper 1981).

$$
\llbracket \text { four outfits } \rrbracket=\lambda \mathrm{i} \lambda \mathrm{P}[\#(\lambda \mathrm{u}[\llbracket \text { outfit } \rrbracket(\mathrm{i})(\mathrm{u}) \wedge \mathrm{P}(\mathrm{i})(\mathrm{u})]) \geq 4]
$$

The predicate make $u$ with $u^{\prime}$ is quite complex in its own right. For our purpose we understand it as follows: The agent selects parts of $\mathrm{u}^{\prime}$ and creates an $u$ out of these parts that did not exist immediately before. Following von Stechow (2001) on verbs of creation, I express this as in (9), where $i^{\prime} \angle i$ stands for ' $i$ ' immediately precedes i", EXIST(i) identifies the entities that exist at the index i, and CONST(i)(u) is the set of entities that $u$ consists of at $i$.

(9) 【make ... with ... 》

$$
\begin{aligned}
& =\lambda i \lambda u \lambda u^{\prime} \lambda u^{\prime \prime} \exists i^{\prime}\left[i^{\prime} \angle \mathrm{i} \wedge \neg \operatorname{EXIST}\left(i^{\prime}\right)(\mathrm{u}) \wedge\right. \\
& \left.\left.\mathrm{u}^{\prime \prime} \text { causes in } \mathrm{i}^{\prime}:[\operatorname{EXIST}(\mathrm{i})(\mathrm{u})] \wedge \forall \mathrm{u}^{\prime \prime \prime}\left[\mathrm{u}^{\prime \prime \prime} \in \operatorname{CONST}(\mathrm{i})(\mathrm{u}) \rightarrow \mathrm{u}^{\prime \prime \prime} \sqsubseteq \mathrm{u}^{\prime}\right]\right]\right]
\end{aligned}
$$

\footnotetext{
${ }^{9}$ Thanks to Sebastian Löbner for pointing out the semantic complexities of outfit.

${ }^{10}$ In the functional reading, as present in expressions like outfit of Mary, the intension of outfit would consist in a function OUTFIT-OF $=\lambda \mathrm{i} \lambda \mathrm{u}^{\prime} \mathrm{\iota u}[\mathrm{u}$ consists of articles of clothing worn by the person $u^{\prime}$ in $i$, provided that the satisfying the dress code in i]. The sortal meaning we are interested in here can be derived by existential binding over the person argument $u^{\prime}$, as $\lambda \mathrm{i} \lambda \mathrm{u} \exists \mathrm{u}^{\prime}\left[\mathrm{OUTFIT-OF}(\mathrm{i})\left(\mathrm{u}^{\prime}\right)\right.$ $=\mathrm{u}]$, 'outfit of a person'.
} 
To illustrate, consider the following example, where this refers to the sum individual of two shirts $\mathrm{s}_{1}, \mathrm{~s}_{2}$ and two pants, $\mathrm{p}_{1}$ and $\mathrm{p}_{2}$, rendered as $\mathrm{s} 1 \sqcup \mathrm{s} 2 \sqcup \mathrm{p} 1 \sqcup \mathrm{p} 2$.

(10) 【John made an outfit with this $\rrbracket\left(\mathrm{i}_{0}\right)$

$=\exists \mathrm{i}\left[\mathrm{i}<\mathrm{i}_{0} \wedge \exists \mathrm{u}\left[\llbracket\right.\right.$ outfit $\rrbracket(\mathrm{i})(\mathrm{u}) \wedge \exists \mathrm{i}^{\prime}\left[\mathrm{i}^{\prime} \angle \mathrm{i} \wedge \neg \operatorname{EXIST}\left(\mathrm{i}^{\prime}\right)(\mathrm{u}) \wedge\right.$

[John causes in $i^{\prime}:[\operatorname{EXIST}(\mathrm{i})(\mathrm{u})] \wedge$

$\left.\left.\left.\forall \mathrm{u}^{\prime \prime \prime}\left[\mathrm{u}^{\prime \prime \prime} \in \operatorname{CONST}(\mathrm{i})(\mathrm{u}) \rightarrow \mathrm{u}^{\prime \prime \prime} \sqsubseteq \mathrm{s}_{1} \sqcup \mathrm{s}_{2} \sqcup \mathrm{p}_{1} \sqcup \mathrm{p}_{2}\right]\right]\right]\right]$

This means that at some time $\mathrm{i}$ in the past relative to $\mathrm{i}_{0}$, John caused at an immediately preceding index $i^{\prime}$ that at $i$ an entity is created that is an outfit at $i$, such that the things the outfit consists of are part of the two shirts and two pairs of pants referred to by this. We are not interested in a fine-grade analysis of causality here-this would state that there is some action on John's part at or before $i^{\prime}$ such that without that action the result, here that $\mathrm{u}$ exists, would not have been achieved (cf. Lewis 1973, based on the analysis of causality by David Hume). Also, we will not go into the CONST relation for now, but note here that it must allow for a newly created outfit to consist of parts that existed already before. Finally, it should be noted that we often understand (10) in a way that the person that wears the outfit at $\mathrm{i}$ is the agent, John, himself-but this need not be the case, e.g. if John is a fashion designer.

It is obvious that when $s_{1}, s_{2}, p_{1}, p_{2}$ are the only articles of clothing, and any combination of a shirt and a pair of pants satisfies the dress code requirements for an outfit, the four combinations $\mathrm{s}_{1} \sqcup \mathrm{p}_{1}, \mathrm{~s}_{1} \sqcup \mathrm{p}_{2}, \mathrm{~s}_{2} \sqcup \mathrm{p}_{1}, \mathrm{~s}_{2} \sqcup \mathrm{p}_{2}$ are the only acceptable ones that can be used to create outfits. And as the same article of clothing cannot serve as part of two different outfits at the same index, sentence (11) cannot be true at any particular index $i_{0}$.

(11) 【John made four outfits with this $\rrbracket\left(\mathrm{i}_{0}\right)$ $=\exists \mathrm{i}\left[\mathrm{i}<\mathrm{i}_{0} \wedge\left[\#\left(\lambda \mathrm{u}\left[\llbracket\right.\right.\right.\right.$ outfits $\rrbracket(\mathrm{i})(\mathrm{u}) \wedge \exists \mathrm{i}^{\prime}\left[\mathrm{i}^{\prime} \angle \mathrm{i} \wedge \neg \operatorname{EXIST}\left(\mathrm{i}^{\prime}\right)(\mathrm{u}) \wedge\right.$

[John causes in $\mathrm{i}^{\prime}:$ [EXIST(i)(u)] $\wedge$ $\left.\left.\left.\left.\forall \mathrm{u}^{\prime \prime \prime}\left[\mathrm{u}^{\prime \prime \prime} \in \operatorname{CONST}(\mathrm{i})(\mathrm{u}) \rightarrow \mathrm{u}^{\prime \prime \prime} \sqsubseteq \mathrm{s}_{1} \sqcup \mathrm{s}_{2} \sqcup \mathrm{p}_{1} \sqcup \mathrm{p}_{2}\right]\right]\right]\right) \geq 4\right]$

This is because (11) requires that four outfits exist at time i. We might think that the modality of the original example (2) helps. However, this is not the case. Consider the following simple interpretation of possibility:

(12) $\llbracket$ it is possible $=\lambda \mathrm{i}^{\prime} \lambda \mathrm{p} \exists \mathrm{i} \in \mathrm{R}\left(\mathrm{i}^{\prime}\right)[\mathrm{p}(\mathrm{i})]$

First, the modal may have wide scope with respect to the DP, resulting in the following interpretation at an index $\mathrm{i}_{0}$.

(13) $\llbracket[$ it is possible $]\left[[\text { four outfits }]_{\mathrm{i}}\left[\right.\right.$ to make $\mathrm{t}_{\mathrm{i}}$ with this $\left.]\right] \rrbracket\left(\mathrm{i}_{0}\right)$

$=\lambda \mathrm{i}\left[\llbracket\right.$ it is possible $\rrbracket(\mathrm{i})\left(\lambda \mathrm{i}^{\prime}\left[\llbracket\right.\right.$ four outfits $\rrbracket\left(\mathrm{i}^{\prime}\right)\left(\llbracket\right.$ to make with this $\left.\left.\left.\left.\rrbracket\left(\mathrm{i}^{\prime}\right)\right)\right]\right)\right]\left(\mathrm{i}_{0}\right)$

$=\exists \mathrm{i} \in \mathrm{R}\left(\mathrm{i}_{0}\right)\left[\#\left(\lambda \mathrm{u}\left[\llbracket\right.\right.\right.$ outfit $\rrbracket(\mathrm{i})(\mathrm{u}) \wedge \exists \mathrm{i}^{\prime}\left[\mathrm{i}^{\prime} \angle \mathrm{i} \wedge \neg \operatorname{EXIST}\left(\mathrm{i}^{\prime}\right)(\mathrm{u}) \wedge\right.$

$\exists \mathrm{u}^{\prime \prime}\left[\mathrm{u}^{\prime \prime}\right.$ causes in $\mathrm{i}^{\prime}:[\operatorname{EXIST}(\mathrm{i})(\mathrm{u})] \wedge$

$\left.\left.\left.\left.\left.\forall \mathrm{u}^{\prime \prime \prime}\left[\mathrm{u}^{\prime \prime \prime} \in \operatorname{CONST}(\mathrm{i})(\mathrm{u}) \rightarrow \mathrm{u}^{\prime \prime \prime} \sqsubseteq \mathrm{s}_{1} \sqcup \mathrm{s}_{2} \sqcup \mathrm{p}_{1} \sqcup \mathrm{p}_{2}\right]\right]\right]\right]\right) \geq 4\right]$ 
This states that there is some index $i^{\prime}$ accessible from $i_{0}$ such that the cardinality of outfits made with the two shirts and two pairs of pants at $i^{\prime}$ is at least four. Clearly, this is not the intended reading: The sentence does not refer to a possible index in which, for example, a seamstress undoes the two shirts and two pants and makes four shirts and four pants out of them, thus creating four outfits in that world.

Second, the DP might have wide scope with respect to the modal. This results in the following interpretation:

(14)

$$
\begin{aligned}
& \llbracket[\text { four outfits }]_{\mathrm{i}}\left[\text { it is possible }\left[\text { to make } \mathrm{t}_{\mathrm{i}} \text { with this }\right]\right] \rrbracket\left(\mathrm{i}_{0}\right) \\
& =\lambda \mathrm{i}\left[\llbracket \text { four outfits } \rrbracket ( \mathrm { i } ) \left(\lambda \mathrm{u}\left[\llbracket \text { it is possible } \rrbracket(\mathrm{i})\left(\lambda \mathrm{i}^{\prime}\left[\llbracket \text { to make with this } \rrbracket\left(\mathrm{i}^{\prime}\right)(\mathrm{u})\right]\right)\right)\left(\mathrm{i}_{0}\right)\right.\right. \\
& =\#\left(\lambda \mathrm { u } \left[\llbracket \text { outfit } \rrbracket ( \mathrm { i } _ { 0 } ) ( \mathrm { u } ) \wedge \exists \mathrm { i } \in \mathrm { R } ( \mathrm { i } _ { 0 } ) \wedge \exists \mathrm { i } ^ { \prime } \left[\mathrm{i}^{\prime} \angle \mathrm{i} \wedge \neg \operatorname{EXIST}\left(\mathrm{i}^{\prime}\right)(\mathrm{u}) \wedge\right.\right.\right. \\
& \exists \mathrm{u}^{\prime \prime}\left[\mathrm{u}^{\prime \prime} \text { causes in } \mathrm{i}^{\prime}:[\operatorname{EXIST}(\mathrm{i})(\mathrm{u})] \wedge\right. \\
& \left.\left.\left.\forall \mathrm{u}^{\prime \prime \prime}\left[\mathrm{u}^{\prime \prime \prime} \in \operatorname{CONST}(\mathrm{i})(\mathrm{u}) \rightarrow \mathrm{u}^{\prime \prime \prime} \subseteq \mathrm{s}_{1} \sqcup \mathrm{s}_{2} \sqcup \mathrm{p}_{1} \sqcup \mathrm{p}_{2}\right]\right]\right]\right) \geq 4
\end{aligned}
$$

This result is even worse because it states that there exist four outfits made with the two shirts and two pairs of pants at the index of interpretation $i_{0}$ itself.

\section{An Individual Concept Analysis}

What went wrong? The problem is with the analysis of outfits as simple entities, type e. The representations in (11), (13) and (14) force us to assume that there are four outfits made of the two shirts and two pairs of pants at the same time. The solution I would like to propose is that outfits and their ilk are rather individual concepts, that is, functions from indices to entities, type se. Such functions may be partial, that is, they need not be defined for a particular index. In this case we say that the individual concept does not "exist" at that index, in the sense that it does not have a value. But it exists as a concept, as a function from indices to entities, and this concept may have properties, like being an outfit.

Individual concepts were used by Gupta (1980) to model the meaning of sentences like National Airlines served two million passengers in 1975. Gupta pointed out that this does not entail that National Airlines served two million persons, as one and the same person can perform the role of a passenger multiple times. Gupta's solutionwhich analyzes passengers as individual concepts defined only for the time of a person's flight - is problematic, as we find the same interpretation for sentences like National Airlines served two million persons in 1975, and persons, unlike passengers, are not individuated by flights (cf. Krifka 1990). But individual concepts appear to be well-suited for configurations.

To illustrate the individual concept analysis, take the four outfits one can make with the two shirts $s_{1}, s_{2}$ and the two pairs of pants $\mathrm{p}_{1}, \mathrm{p}_{2}$. I make use of the notation introduced in Heim and Kratzer (1998) according to which an expression of the form $\lambda v$. Restriction[v]. [Value[v]] denotes the (possibly partial) function from entities of 
the type of $\mathrm{v}$ that is only defined for arguments for which Restriction[v] holds; if defined, the function gives as value whatever is specified in Value[v].

$$
\begin{aligned}
& \mathrm{o}_{1}=\lambda \mathrm{i} . \mathrm{s}_{1} \text { and } \mathrm{p}_{1} \text { dress a person following cultural norms in i. }\left[\mathrm{s}_{1} \sqcup \mathrm{p}_{1}\right] \\
& \mathrm{o}_{2}=\lambda \mathrm{i} . \mathrm{s}_{1} \text { and } \mathrm{p}_{2} \text { dress a person following cultural norms in i. }\left[\mathrm{s}_{1} \sqcup \mathrm{p}_{2}\right] \\
& \mathrm{o}_{3}=\lambda \mathrm{i} . \mathrm{s}_{2} \text { and } \mathrm{p}_{1} \text { dress a person following cultural norms in i. }\left[\mathrm{s}_{2} \sqcup \mathrm{p}_{1}\right] \\
& \mathrm{o}_{4}=\lambda \mathrm{i} . \mathrm{s}_{2} \text { and } \mathrm{p}_{2} \text { dress a person following cultural norms in i. }\left[\mathrm{s}_{2} \sqcup \mathrm{p}_{2}\right]
\end{aligned}
$$

For example, $\mathrm{o}_{1}$ is an individual concept that is only defined for indices $\mathrm{i}$ if the entities $\mathrm{s}_{1}$ and $\mathrm{p}_{1}$ dress a person following the dress code in $\mathrm{i}$; if defined, $\mathrm{o}_{1}$ maps to the sum entity consisting of the entities $s_{1}$ and $p_{1}$. As one piece of clothing cannot be part of two outfits at any given index, the outfit concepts $\mathrm{o}_{1}, \mathrm{o}_{2}$ and $\mathrm{o}_{3}$ have non-overlapping domains and cannot exist at the same indices; only the outfits $\mathrm{o}_{1}$ and $\mathrm{o}_{4}$ (and the outfits $\mathrm{O}_{2}$ and $\mathrm{o}_{3}$ ) can co-exist, as they consist of non-overlapping parts.

It is clear what it means that an individual concept $x$ exists at an index: It exists precisely at the indices in its domain. That is, if $\mathrm{x}$ is an individual concept, type se, and EXIST is a predicate of individual concepts, type $s(s e) t$, then we have EXIST(i)(x) $=1$ iff $\mathrm{i} \in \operatorname{DOM}(\mathrm{x})$. For example, the concept $\mathrm{o}_{1}$ exists for all indices $\mathrm{i}$ for which $\mathrm{o}_{1}(\mathrm{i})$ is defined, that is, for which $s_{1} \sqcup \mathrm{p}_{1}$ dresses a person following cultural norms in $\mathrm{i}$. This means that $\mathrm{o}_{1}$ does not exist for all indices $\mathrm{i}$ at which $\mathrm{s}_{1} \sqcup \mathrm{p}_{1}$ does not dress a person, or else $s_{1} \sqcup \mathrm{p}_{1}$ dresses a person but the cultural norms are so different that this does not follow the dress code. Consequently, the outfit $\mathrm{o}_{1}$ probably is of a rather punctuated or spotty nature: It may exist on May 1, then again on July 22, and on September 7 , the times when $o_{1}$ is actually used to dress a person, but not in the times in between.

Gupta analyzed common nouns as properties of individual concepts, type s(se)t, and we will follow him in this respect. The common noun outfit applies to individual concepts like $\mathrm{o}_{1}$ in (15), and not to simple entities. I first give the extension of this common noun meaning at an index $\mathrm{i}_{0}$ in the set notation; it is of type (se)t.

$$
\begin{aligned}
& \text { 【outfit } \rrbracket\left(\mathrm{i}_{0}\right) \\
& =\{\lambda \mathrm{i} \text {. } \mathrm{u} \text { consists of articles of clothing worn by a person in } \mathrm{i}, \text { where the } \\
& \text { articles and their arrangement in i satisfy the accepted dress code } \\
& \left.\quad \text { in } \mathrm{i}_{0} \cdot[\mathrm{u}] \mid \mathrm{u} \in \mathrm{D}_{\mathrm{e}}\right\}
\end{aligned}
$$

This is the set of all functions from indices $i$ to entities $u$ in the universe $D_{e}$ whose parts are worn by a person in $i$ and form an acceptable dress according to the standards of $i_{0}$. The condition about the parts of $u$ are expressed by way of a restriction of this function. This accounts for the fact that there might be indices at which we do not consider the arrangement of a striped shirt and a checkered pair of pants a suitable outfit.

We can describe the intension of outfit as follows, in a first approximation:

$$
\begin{array}{r}
\llbracket \text { outfit } \rrbracket=\lambda \mathrm{i}^{\prime} \lambda \mathrm{x} \forall \mathrm{i} \in \mathrm{DEF}(\mathrm{x})[\mathrm{x}(\mathrm{i}) \text { consists of articles of clothing worn by a person } \\
\text { in } \mathrm{i} \text {, where the articles and their arrangement in } \mathrm{i} \\
\text { satisfy the accepted dress code in } \left.i^{\prime}\right]
\end{array}
$$


Notice that it might happen that at a given index $\mathrm{i}_{0}$, all the individual concepts in $\llbracket$ outfit $\rrbracket\left(i_{0}\right)$ are such that they are not defined for $i_{0}$, because none of them is worn in an acceptable way. Nevertheless, $\llbracket$ outfit $\rrbracket\left(\mathrm{i}_{0}\right)$ is not empty in this case. To give a concrete example, assume a set of seven indices $i_{0}, \ldots i_{6}$, and assume that the four outfits mentioned in (15) are the following functions:

$$
\begin{aligned}
& \mathrm{o}_{1}=\left[\mathrm{i}_{1} \rightarrow \mathrm{s}_{1} \sqcup \mathrm{p}_{1}, \mathrm{i}_{2} \rightarrow \mathrm{s}_{1} \sqcup \mathrm{p}_{1}\right] \quad \text { indices: } \mathrm{i}_{0} \quad \mathrm{i}_{1} \quad \mathrm{i}_{2} \quad \mathrm{i}_{3} \quad \mathrm{i}_{4} \quad \mathrm{i}_{5} \quad \mathrm{i}_{6}
\end{aligned}
$$

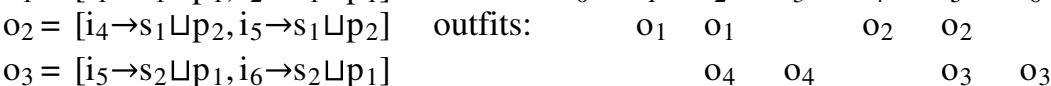

$$
\begin{aligned}
& \mathrm{o}_{4}=\left[\mathrm{i}_{2} \rightarrow \mathrm{s}_{2} \sqcup \mathrm{p}_{2}, \mathrm{i}_{3} \rightarrow \mathrm{s}_{2} \sqcup \mathrm{p}_{2}\right]
\end{aligned}
$$

Notice that $\mathrm{o}_{1}$ and $\mathrm{o}_{4}$ both are realized at $\mathrm{i}_{2}$, and $\mathrm{o}_{2}$ and $\mathrm{o}_{3}$ both are realized at $\mathrm{i}_{5}$, but that $\mathrm{o}_{1}$ and $\mathrm{o}_{3}$ as well as $\mathrm{o}_{3}$ and $\mathrm{o}_{4}$ do not co-exist. At $\mathrm{i}_{0}$ no outfit is realized at all. But the noun outfit denotes for all indices, including $\mathrm{i}_{0}$, the set of all these individual concepts, if what qualifies as outfit is the same for all indices. The meaning of outfit is a constant property.

$$
\llbracket \text { outfit } \rrbracket=\lambda i \in\left\{\mathrm{i}_{0}, \ldots \mathrm{i}_{6}\right\} \lambda x\left[\mathrm{x} \in\left\{\mathrm{o}_{1}, \mathrm{o}_{2}, \mathrm{o}_{3}, \mathrm{o}_{4}\right\}\right]
$$

The meaning in (17) is not restrictive enough. In a situation like (18) it does not prevent us from calling, say, the function $\left[i_{1} \rightarrow s_{1} \sqcup p_{1}\right]$ an outfit as well that is distinct from $o_{1}$, as it is only defined for the index $i_{1}$. Clearly, outfits are maximal with respect to indices, in the sense that for every index $i$ at wich $s_{1} \sqcup p_{1}$ is worn by a person, satisfying the dress code, this index belongs to the domain of the individual concept. Furthermore, in a situation like (18) we could not count an individual concept like $\left[\mathrm{i}_{1} \rightarrow \mathrm{s}_{1} \sqcup \mathrm{p}_{1}, \mathrm{i}_{4} \rightarrow \mathrm{s}_{1} \sqcup \mathrm{p}_{2}\right.$ ] as an outfit, because it maps its indices to different articles of clothing. This violates the identity criteria that we normally assume for individual concepts, that they consist of the same entities, or the same substance. ${ }^{11}$ A spelled-out version of (17) that includes these general conditions for cognitively relevant individual concepts would read as in (20), where the second line guarantees substance identity, and the third line maximality.

$$
\begin{array}{rlrl}
\llbracket \text { outfit }^{\prime} \rrbracket= & \lambda \mathrm{i}^{\prime} \lambda \mathrm{x}\left[(17)\left(\mathrm{i}^{\prime}\right)(\mathrm{x}) \wedge\right. & \\
& \forall \mathrm{i}, \mathrm{i}^{\prime \prime} \in \operatorname{DEF}(\mathrm{x})\left[(17)\left(\mathrm{i}^{\prime}\right)(\mathrm{x}) \rightarrow \mathrm{x}(\mathrm{i})=\mathrm{x}\left(\mathrm{i}^{\prime \prime}\right)\right] \wedge & & \text { same substance } \\
& \left.\neg \exists \mathrm{x}^{\prime}\left[(17)\left(\mathrm{i}^{\prime}\right)\left(\mathrm{x}^{\prime}\right) \wedge \operatorname{DOM}\left(\mathrm{x}^{\prime}\right) \subset \operatorname{DOM}(\mathrm{x})\right]\right] & & \text { maximality }
\end{array}
$$

The semantic type of outfit, a property that refers to individual concepts, would have to work with the expressions outfit combines with. For example, the predicate wear would have the following interpretation, where the object concept $\mathrm{x}$ is reduced to the value of $\mathrm{x}$ at the index of interpretation.

$$
\llbracket w e a r \rrbracket=\lambda \mathrm{i} \lambda \mathrm{x} \lambda \mathrm{u}[\mathrm{u} \text { is wearing } \mathrm{x}(\mathrm{i}) \text { at } \mathrm{i}]
$$

\footnotetext{
${ }^{11}$ This is no quite true, as incremental changes are sometimes possible, cf. e.g. the example of the ship of Theseus, whose planks are replaced one by one over time, or living creatures that undergo metabolism, or entities like waves that consist in an ever-changing configuration. In all such examples there must be additional criteria of identity beyond material constituency.
} 
Non-extensional predicates like rise or change are not reducible in this way (cf. Montague 1973). ${ }^{12}$ This also applies to predicates of creation. The verb make states that an agent causes an individual concept to be realized at an index. For example, if John makes outfit $o_{1}$ at index $i$ then John causes that at $i, o_{1}$ becomes defined. This presupposes that during the making of $\mathrm{i}$, the individual concept $\mathrm{o}_{1}$ was not defined (one cannot be making something that exists already) and involves some action by the agent on the parts that $\mathrm{o}_{1}$ refers to, $\mathrm{s}_{1} \sqcup \mathrm{p}_{1}$, during the time before $\mathrm{i}$. The essential parts of this is captured in the following interpretation.

$$
\begin{aligned}
& \llbracket \text { make ... with ... \} } \\
{\left.=\lambda \mathrm{i} \lambda \mathrm{x} \lambda \mathrm{u} \lambda \mathrm{u}^{\prime} \exists \mathrm{x}^{\prime} \exists \mathrm{i}^{\prime}\left[\mathrm{i}^{\prime} \angle \mathrm{i} \wedge \neg \mathrm{i}^{\prime} \in \operatorname{DOM}(\mathrm{x}) \wedge \mathrm{u}^{\prime} \text { causes in } \mathrm{i}^{\prime}:[\mathrm{i} \in \operatorname{DOM}(\mathrm{x})] \wedge \mathrm{x}(\mathrm{i}) \sqsubseteq \mathrm{u}\right]\right]}
\end{aligned}
$$

This states that at $i^{\prime}$ the individual concept $\mathrm{x}$ is not realized, but the agent $\mathrm{u}^{\prime}$ causes that it is realized at the immediately following index $i$, where $x(i)$ consists of parts of $\mathrm{u}$.

The DP four outfits is interpreted as follows in the Generalized Quantifier analysis, where $\mathrm{P}$ is a variable for properties of individual concepts, type $\mathrm{s}(\mathrm{se}) \mathrm{t}$.

$$
\llbracket[D P \text { four outfits }] \rrbracket=\lambda \mathrm{i} \lambda \mathrm{P}[\#(\lambda \mathrm{x}[\llbracket \text { outfit } \rrbracket(\mathrm{i})(\mathrm{x}) \wedge \mathrm{P}(\mathrm{i})(\mathrm{x})]) \geq 4]
$$

We now can give an appropriate interpretation to our example. It states that there are four outfit concepts such that there are accessible indices at which these outfits are made. Notice that the predication is understood as distributive: For each of these individual concepts, there is an accessible index at which it can be made.

$$
\begin{aligned}
& \llbracket[\text { four outfits }] \lambda \mathrm{t}[\text { it is possible }[\text { to make } \mathrm{t} \text { with this }]] \rrbracket\left(\mathrm{i}_{0}\right) \\
& =\lambda \mathrm{i}\left[\llbracket \text { four outfits } \rrbracket(\mathrm{i})\left(\lambda \mathrm{x}\left[\llbracket \text { it is possible } \rrbracket(\mathrm{i})\left(\lambda \mathrm{i}^{\prime}\left[\llbracket \text { to make with this } \rrbracket\left(\mathrm{i}^{\prime}\right)(\mathrm{x})\right]\right)\right) \rrbracket\right]\left(\mathrm{i}_{0}\right)\right. \\
& =\llbracket \text { four outfits } \rrbracket\left(\mathrm{i}_{0}\right)\left(\lambda \mathrm { x } \left[\llbracket \text { it is possible } \rrbracket\left(\mathrm{i}_{0}\right)\left(\lambda \mathrm{i}^{\prime}\left[\llbracket \text { to make with this } \rrbracket\left(\mathrm{i}^{\prime}\right)(\mathrm{x})\right]\right)\right.\right. \\
& =\#\left(\lambda \mathrm { x } \left[\llbracket \text { outfits } \rrbracket\left(\mathrm{i}_{0}\right)(\mathrm{x}) \wedge \llbracket \text { it is possible } \rrbracket\left(\mathrm{i}_{0}\right)\left(\lambda \mathrm{i}^{\prime}\left[\llbracket \text { to make with this } \rrbracket\left(\mathrm{i}^{\prime}\right)(\mathrm{x})\right]\right) \geq 4\right.\right. \\
& =\#\left(\lambda \mathrm { x } \left[\mathrm{x} \in\left\{\mathrm{o}_{1}, \mathrm{o}_{2}, \mathrm{o}_{3}, \mathrm{o}_{4}\right\} \wedge\right.\right. \\
& \quad \exists \mathrm{i}^{\prime} \in \mathrm{R}\left(\mathrm{i}_{0}\right) \exists \mathrm{u}^{\prime} \exists \mathrm{i}^{\prime \prime}\left[\mathrm{i}^{\prime \prime} \angle \mathrm{i}^{\prime} \wedge \neg \mathrm{i}^{\prime \prime} \in \mathrm{DOM}(\mathrm{x}) \wedge\right. \\
& \left.\left.\left.\quad\left[\mathrm{u}^{\prime} \text { causes in } \mathrm{i}^{\prime \prime}:\left[\mathrm{i}^{\prime} \in \mathrm{DOM}(\mathrm{x})\right] \wedge \mathrm{x}\left(\mathrm{i}^{\prime}\right) \sqsubseteq \mathrm{s}_{1} \sqcup \mathrm{s}_{2} \sqcup \mathrm{p}_{1} \sqcup \mathrm{p}_{2},\right]\right]\right]\right) \geq 4
\end{aligned}
$$

This is true iff for each of the four individual concepts $x$ there is an index $i^{\prime}$ accessible from $i_{0}$ such that $x$ is realized by someone at $i^{\prime}$, and $x\left(i^{\prime}\right)$ is part of the two shirts and two pants. It is crucial that this does not entail that there is an index at which all four individual concepts are realized simultaneously. In particular, (23) is compatible with a situation in which only two outfits can be realized at a time.

It should be pointed out that there is also a consistent interpretation for the following example, if the quantifier scopes over the past tense operator:

\footnotetext{
${ }^{12}$ The verb change can be used for outfits in its functional sense, as in Mary changed her outfit. Let us represent the functional reading OUTFIT-OF as $\lambda \mathrm{i} \lambda \mathrm{u} u \mathrm{x}\left[\llbracket o u t f i t^{\prime} \rrbracket(\mathrm{i})(\mathrm{x}) \wedge \mathrm{u}\right.$ is wearing $\mathrm{x}(\mathrm{i})$ at i] (alternatively, we can start with a functional reading and derive the sortal reading, as in footnote 10). Then Mary changes her outfit is true at $\mathrm{i}$ iff there is an $\mathrm{i}^{\prime}$ shortly before $\mathrm{i}$, and an $\mathrm{i}^{\prime \prime}$ shortly after, such that OUTFIT-OF(i')(Mary) $\neq$ OUTFIT-OF(i")(Mary).
} 
(25)

$$
\begin{aligned}
& \llbracket \text { John made four outfits with this } \rrbracket\left(\mathrm{i}_{0}\right) \\
& =\llbracket[\text { four outfits }] \lambda \mathrm{t} \text { PAST }[\text { John maket with this }]] \rrbracket\left(\mathrm{i}_{0}\right) \\
& =\#\left(\lambda \mathrm { x } \left[\mathrm{x} \in\left\{\mathrm{o}_{1}, \mathrm{o}_{2}, \mathrm{o}_{3}, \mathrm{o}_{4}\right\} \wedge\right.\right. \\
& \quad \exists \mathrm{i}^{\prime}\left[\mathrm{i}^{\prime}<\mathrm{i}_{0} \wedge \exists \mathrm{i}^{\prime \prime}\left[\mathrm{i}^{\prime \prime} \angle \mathrm{i}^{\prime} \wedge \neg \mathrm{i}^{\prime \prime} \in \operatorname{DOM}(\mathrm{x}) \wedge\right.\right. \\
& \left.\left.\left.\quad\left[\mathrm{John} \text { causes in } \mathrm{i}^{\prime \prime}:\left[\mathrm{i}^{\prime} \in \operatorname{DOM}(\mathrm{x})\right] \wedge \mathrm{x}\left(\mathrm{i}^{\prime}\right) \sqsubseteq \mathrm{s}_{1} \sqcup \mathrm{s}_{2} \sqcup \mathrm{p}_{1} \sqcup \mathrm{p}_{2},\right]\right]\right]\right) \geq 4
\end{aligned}
$$

The sentence can be true at a given index, as the individual concepts may come into existence at different times; notice that the existential quantifier $\exists \mathrm{i}^{\prime} \ldots$ has scope under the quantifier four outfits.

In this section I have proposed a semantic interpretation of sentences like (2) that stays close to the standard Generalized Quantifier analysis of sentences with numerically modified nouns like four outfits. The only substantial change is that the noun outfit does not refer to ordinary individuals, but to individual concepts. In the next section we will argue that the individual concept analysis should be generalized; it should apply to entities such as shirts and pairs of pants as well.

\section{Generalizing the Individual Concept Analysis}

\subsection{Is Everything an Individual Concept?}

There are good reasons to apply the individual concept analysis to other individuals than to just configurational individuals, like outfits. Take, for example, Ludwig Wittgenstein; he can be represented by an individual concept that maps all indices $i$ at which Wittgenstein exists to Wittgenstein - in our world, these are all indices from April 26, 1889 to April 29, 1951. In contrast to the domains of configurations that fade in and out of existence, this is a convex set of indices: If $i$ and $i^{\prime}$ are indices of the same possible history that are in this set, and if $i^{\prime \prime}$ is an index of the same possible history that is temporally in-between $i$ and $i^{\prime}$, then $i^{\prime \prime}$ is in this set as well. ${ }^{13}$ As another example, take role concepts like the tallest woman, or the Pope. In contrast to configurations, such concepts may refer to different entities for different indices. As a third example, take individual concepts like the denotation of the gifted mathematician that John claims to be (cf. Grosu and Krifka 2008). Such expressions denote individual concepts that refer to the same entity, but are restricted to those indices that are compatible with John's claims. The individual concept analysis also affords for analyses of concepts like a wave (of water), which has a convex set of indices but maps these indices to ever-changing water entities.

If regular individuals are also based on individual concepts, then this also should hold for pants and shirts. After all, they certainly are created, and destroyed. As

\footnotetext{
${ }^{13}$ The individual concept view opens a new way to deal with modified names, like (the) young Mozart (cf. Paul 1994), as a subconcept; the term refers to the same entity as Mozart but is only defined for those indices at which Mozart was young.
} 
individual concepts, they differ from outfits insofar as they have a convex domain: Whenever it holds that $i, i^{\prime} \in \operatorname{DOM}(x)$, then for all $i^{\prime \prime}$ that are temporally in between, $\mathrm{i}<\mathrm{i}^{\prime \prime}<\mathrm{i}$, it also holds that $\mathrm{i}^{\prime \prime} \in \operatorname{DOM}(\mathrm{x})$. But what, then, do individual concepts map their indices to? We might think of the substance or matter they consist of (this corresponds to the $h$ homomorphism in Link (1983) that maps objects to matter). Hence, the shirt $\mathrm{s}_{1}$ would be also of type se, a function from indices to the matter the shirt consists of, provided that this matter forms a shirt at these indices. Moreover, for concrete objects like shirts we have to assume additional conditions, namely that the matter is more or less the same between indices, allowing for occasional small changes like replacing a button in the case of a shirt, or metabolic exchanges of matter in the case of living creatures.

The outfit $\mathrm{o}_{1}$ consisting of the shirt $\mathrm{s}_{1}$ and the pair of pants $\mathrm{p}_{1}$, which are analyzed as concrete object concepts themselves, can then be defined as follows:

$$
\left.\mathrm{o}_{1}=\lambda \text { i. } \mathrm{s}_{1} \text { and } \mathrm{p}_{1} \text { dress a person following cultural norms in i. [ } \mathrm{s}_{1}(\mathrm{i}) \sqcup \mathrm{p}_{1}(\mathrm{i})\right]
$$

That is, $\mathrm{o}_{1}$ maps every index i for which it is defined to the same stuff as the join of the stuff of $s_{1}$ and $p_{1}$ at $i$. In general, we would have the following interpretation of outfit as a property of individual concepts; an appropriate maximalization as in (20) would have to be added.

(27) $\llbracket$ outfit $\rrbracket=\lambda \mathrm{i}^{\prime} \lambda \mathrm{x} \forall \mathrm{i} \in \mathrm{DEF}(\mathrm{x})[\mathrm{x}$ consists of articles of clothing worn by a person in $i$, where the articles and their arrangement in $\mathrm{i}$ satisfy the accepted dress code in $\left.i^{\prime}\right]$

The only difference to (17) is that $\mathrm{x}$, not $\mathrm{x}(\mathrm{i})$, is required to consist of articles of clothing. That is, for each outfit $x$ there must be articles of clothing $x_{1}, x_{2}, \ldots x_{n}$ such that $\mathrm{x}=\mathrm{x}_{1} \sqcup \mathrm{x}_{2} \sqcup \ldots \sqcup \mathrm{x}_{\mathrm{n}}$. The material join operation for individual concepts is defined as follows:

$$
x \sqcup y=\lambda i[x(i) \sqcup y(i)]
$$

This is an individual concept that is defined for all indices for which $\mathrm{x}$ and $\mathrm{y}$ are defined, and maps these indices to the sum of $x$ and $y$. This leads to the following definition, where $\sqcup \mathrm{P}$ is the join of all individuals in the set $\mathrm{P}$.

$$
\begin{aligned}
\llbracket \text { outfit } \rrbracket=\lambda \mathrm{i}^{\prime} \lambda \mathrm{x} \exists \mathrm{P} \forall \mathrm{i} \in \operatorname{DEF}(\mathrm{x})[ & \forall \mathrm{y} \in \mathrm{P}\left[\mathrm{y} \text { is an article of clothing in } \mathrm{i}^{\prime}\right] \\
& \wedge \mathrm{x}=\sqcup \mathrm{P} \\
& \wedge \exists \mathrm{z}[\text { person }(\mathrm{i})(\mathrm{z}) \wedge \text { dressed-with(i)(z)(x)} \\
& \left.\left.\wedge \text { satisfies-dress-code }\left(\mathrm{i}^{\prime}\right)(\mathrm{z})(\mathrm{x})\right]\right] .
\end{aligned}
$$

This says that whenever $\mathrm{x}$ is an outfit, then it applies to the same matter as the sum of some set $\mathrm{P}$ of articles of clothing. The sum of the matter of these articles of clothing is the same as the matter of the outfit, but the articles of clothing may be defined for a larger, and typically convex, domain. Even though (28) does not require this 
literally, we can think of each outfit $\mathrm{x}$ being associated with a unique set of articles of clothing P.

\subsection{Coercion to Constituting Parts}

Commenting on an earlier version of this article, Sebastian Löbner suggested an analysis in which entities like outfits are regular entities, type e, instead of individual concepts. The idea is that any combination of entities that can form an outfit is in the extension of outfit; in our example, these are the entities $\mathrm{s}_{1} \sqcup \mathrm{p}_{1}, \mathrm{~s}_{1} \sqcup \mathrm{p}_{2}, \mathrm{~s}_{2} \sqcup \mathrm{p}_{1}, \mathrm{~s}_{2}$ $\sqcup \mathrm{p}_{2}$. This suggests the following interpretation, where outfits are of type e:

(30) 【outfit $\rrbracket\left(\mathrm{i}_{0}\right)=\lambda u \exists i \in \mathrm{R}\left(\mathrm{i}_{0}\right)$ [u is worn by a person in $\mathrm{i}$ in a way that satisfies the dress codes in i]

Note that under this analysis outfit still has an intensional component (an entity s $\sqcup \mathrm{p}$ of type $e$ is an outfit iff in some possible world $i$, a person wears $i$, and this satisfies the dress code in i). But the intensionality is not hard-wired in the notion of objects itself, which remain of type e. They are not lifted to individual concepts, se.

A problem of this analysis is that it does not motivate the use of creation verbs like make, bauen 'build' and create in examples (2)—(5). If the outfit $\mathrm{o}_{1}$ is identical to the sum of entities $\mathrm{s}_{1} \sqcup \mathrm{p}_{1}$, what does it mean to make an outfit? It would perhaps refer to the tailor's sewing of the shirt and the pair of pants, but not to the person that combines this shirt and this pair of pants to wear them together, as suggested in example (2). For this reason, the individual concept analysis, even though it is more complex, appears appropriate.

On the other hand, the interpretation (29) would allow for a straightforward analysis of examples like (30) that are problematic for the interpretations in (17) or (26).

(31) There is an outfit in the wardrobe.

When we understand outfits as entities that are defined only when someone wears them, then (30) could not be true, except in the peculiar case of a person sitting in the wardrobe and wearing an outfit.

I assume that individual concepts with spotted realizations like outfits can be coerced into individual concepts with a more permanent interpretation, and it is these coerced concepts that are involved in sentences like (30). If (30) refers to $o_{1}$, which consists of the concrete individual concepts $\mathrm{s}_{1}$ and $\mathrm{p}_{1}$, then $\mathrm{o}_{1}$ can be coerced into the individual concept $\mathrm{s}_{1} \sqcup \mathrm{p}_{1}$ as defined in (27). Let us call this coercion "grounding". Then (30) states that this sum concept is in the wardrobe.

Grounding in general can be interpreted as the following function: 
(32) Grounding (coercion to parts)

For any individual concept $\mathrm{x}$,

if there are cognitively salient individual concepts $\mathrm{x}_{1}, \ldots \mathrm{x}_{\mathrm{n}}$

such that $\forall i \in D O M(x)\left[x(i)=x_{1}(i) \sqcup \ldots x_{n}(i)\right]$,

then $\mathrm{g}(\mathrm{x})=\mathrm{x}_{1} \sqcup \ldots \sqcup \mathrm{x}_{\mathrm{n}}$

Let us assume that $\mathrm{s}_{1}$ and $\mathrm{p}_{1}$, a shirt and a pair of pants, are modeled by individual concepts as suggested in example (25). The outfit $\mathrm{o}_{1}$ would have the following grounded version:

$$
\mathrm{g}\left(\mathrm{o}_{1}\right)=\lambda \mathrm{i}\left[\mathrm{s}_{1}(\mathrm{i}) \sqcup \mathrm{p}_{1}(\mathrm{i})\right]
$$

This is the individual concept that has the same domain as $o_{1}$ and always refers to the sum of the shirt $s_{1}$ and the pants $p_{1}$. As $s_{1}$ and $p_{1}$ have convex domains, so has $\mathrm{g}\left(\mathrm{o}_{1}\right)$, the grounded version of $\mathrm{x}_{1}$. In particular $\mathrm{g}\left(\mathrm{o}_{1}\right)$ does also exist at indices $\mathrm{i}$ at which no-one is wearing $\mathrm{s}_{1}$ and $\mathrm{p}_{1}$ as an outfit; in our small model (18), $\mathrm{g}\left(\mathrm{o}_{1}\right)$ exists at all indices from $\mathrm{i}_{0}$ to $\mathrm{i}_{6}$. Consequently, $\mathrm{g}\left(\mathrm{o}_{1}\right)$ can have the property of being in the wardrobe at an index like $\mathrm{i}_{0}$ at which $\mathrm{o}_{1}$ does not have any realizations.

It should be noted that, as $\mathrm{g}$ is a function, $\mathrm{g}(\mathrm{x})$ presupposes that there is a unique cognitively most salient way to analyze $\mathrm{x}$ as consisting of concrete objects $\mathrm{x}_{1}, \ldots$ $\mathrm{x}_{\mathrm{n}}$. These are the elements in the set $\mathrm{P}$ in (28). For an outfit, these are the articles of clothing, but not their parts, like the buttons, buckles and the pieces of cloth that they consist of. As they may have existed before the shirt, and may exist after, their sum may lead to an individual concept with a longer duration. If a unique decomposition could not be guaranteed, we would have to model g not as a function, but as a relation that maps $\mathrm{x}$ to different decompositions.

When predicates like be in the wardrobe are applied to individual concepts, then we can assume coercion by the grounding operation triggered by the meaning of the predicate. This is because such predicates can be reduced to the matter that an individual concept realizes at an index, which requires coercion to a more permanent entity $^{14}$ :

$$
\begin{aligned}
& \llbracket \text { an outfit is in the wardrobe } \rrbracket\left(\mathrm{i}_{0}\right) \\
& =\exists \mathrm{x}\left[\llbracket \text { outfit } \rrbracket\left(\mathrm{i}_{0}\right)(\mathrm{x}) \wedge \llbracket \text { in the wardrobe } \rrbracket\left(\mathrm{i}_{0}\right)(\mathrm{g}(\mathrm{x}))\right] \\
& =\exists \mathrm{x}\left[\llbracket \text { outfit } \rrbracket\left(\mathrm{i}_{0}\right)(\mathrm{x}) \wedge \mathrm{g}(\mathrm{x})\left(\mathrm{i}_{0}\right) \text { is in the wardrobe at } \mathrm{i}_{0}\right]
\end{aligned}
$$

This is true at $\mathrm{i}_{0}$ iff $\mathrm{x}$ is an outfit, as before, and the things $\mathrm{x}$ consists of - the shirt $\mathrm{s}_{1}$ and the pair of pants $\mathrm{p}_{1}$ - are in the wardrobe.

Grounded individual concepts can also explain the use of creation verbs to refer to the entities an individual concept consist of, as in the tailor made an outfit. In this case, the object is coerced to its grounded interpretation, due to the knowledge of what tailors typically create.

\footnotetext{
${ }^{14}$ This reduction from individual concepts to stages is similar to the reduction from individuals to stages for stage-level predicates in Carlson (1977).
} 


\subsection{Joining and Counting Individual Concepts}

Grounded individual concepts can be counted, as the examples (34) and (35) show.

(35) There are 100 outfits in this wardrobe.

(36) The supply department ordered 100 new outfits for the employees.

Obviously, the regular individual concept analysis of outfit in (17) does not work, as outfits are not worn by anyone when they are in the wardrobe or when they are ordered. But the entity analysis (29) and the grounded individual concept analysis (31) also are problematic. They would make our examples true in case 10 shirts and 10 pants that can be randomly combined to outfits are in the wardrobe, or are ordered, because they can be configured to 100 outfits. This is illustrated for the grounded individual concept analysis in (37).

$\#\left\{\mathrm{x} \mid \llbracket\right.$ outfit $\rrbracket\left(\mathrm{i}_{0}\right)(\mathrm{x}) \&$ \&in the wardrobe $\left.\rrbracket\left(\mathrm{i}_{0}\right)(\mathrm{g}(\mathrm{x}))\right\}=100$

if $\mathrm{g}(\mathrm{x})=\lambda \mathrm{i}[\mathrm{s}(\mathrm{i}) \sqcup \mathrm{p}(\mathrm{i})], \mathrm{s} \in\left\{\mathrm{s}_{1}, \ldots \mathrm{s}_{10}\right\}, \mathrm{p} \in\left\{\mathrm{p}_{1}, \ldots \mathrm{p}_{10}\right\}$, and both conjuncts are true

The problem here is that configurational individual concepts like outfits defy the usual property of additivity under the current interpretation. Additivity would tell us that if $\mathrm{x}$ is one outfit, and $\mathrm{y}$ is another outfit, then $\mathrm{x}$ and $\mathrm{y}$ together are two outfits. However, as we have seen, we might end up with four outfits. This is because outfits, other than ordinary individuals like shirts and pants, can overlap. The generalized quantifier strategy of representing numbers inherent in (36) cannot rule out such counting of overlapping objects. A theory that fares better is the one proposed in Krifka (1995), according to which count nouns are measure functions that can be applied to sum entities, and specify the number of the things they are applied to. We need something like count noun variants of nominal predicates (marked here by $*$ ) that map individual concepts to numbers, and that follow the rule of additivity:

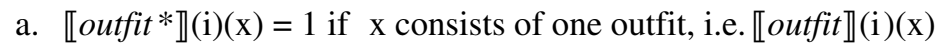

$$
\begin{aligned}
& \text { b. 【outfit } * \rrbracket(\mathrm{i})(\mathrm{x})=\mathrm{n} \wedge \llbracket \text { outfit } * \rrbracket(\mathrm{i})\left(\mathrm{x}^{\prime}\right)=\mathrm{n}^{\prime} \wedge \mathrm{x}, \mathrm{x}^{\prime} \text { do not overlap at } \mathrm{i} \\
& \rightarrow \llbracket \text { outfit } * \rrbracket(\mathrm{i})\left(\mathrm{x} \bigoplus \mathrm{x}^{\prime}\right)=\mathrm{n}+\mathrm{n}^{\prime}
\end{aligned}
$$

Here, $\mathrm{x} \oplus \mathrm{x}^{\prime}$ stands for the sum of the individual concepts $\mathrm{x}$ and $\mathrm{x}^{\prime}$. Notice that (37)(a) and (b) happen to be the same standardization and generalization operations proposed in Krifka (1990) for event-related quantification. Arguably, they belong to the general conceptual tool kit for constructing measure functions in language.

But what does the sum of two individual concepts actually mean? This would need detailed elaboration; I can give here just the basic construction steps. We have to assume that the domain of individual concepts, type se, has a sum structure. Let AIC the set of all atomic individual concepts; this is the set of individual concepts as considered so far. The set of sum individual concepts SIC then is defined as the smallest set such that (a) $\mathrm{AIC} \subseteq \mathrm{SIC}$, and whenever $\mathrm{x}, \mathrm{x}^{\prime} \in \mathrm{SIC}$, then also $\mathrm{x} \oplus \mathrm{x}^{\prime} \in$ 
SIC. Here, $\oplus$ is a join operation that is idempotent, commutative, and associative. We understand it in such a way that the resulting set SIC is homomorphic to the power set of all individual concepts, with atomic individual concepts $\mathrm{x}$ represented by singletons, $\{\mathrm{x}\}$, and sum individual concepts like $\mathrm{x} \oplus \mathrm{x}^{\prime}$ represented by set union, $\{\mathrm{x}\} \cup\left\{\mathrm{x}^{\prime}\right\}=\left\{\mathrm{x}, \mathrm{x}^{\prime}\right\}$.

Sum individual concepts are still functions from indices to entities. In particular, a sum individual concept maps an index to the sum of the parts when they are defined for that index. That is, we require that $\left[x \oplus x^{\prime}\right](i)=x(i) \sqcup x^{\prime}(i)$, if $x$ and $x^{\prime}$ are defined for $i$; $\left[x \oplus x^{\prime}\right](i)=x(i)$, if only $x$ is defined for $i$, and $\left[x \oplus x^{\prime}\right](i)=x^{\prime}(i)$, if only $\mathrm{x}^{\prime}$ is defined for $\mathrm{i}$. Notice that different sum individual concepts can have the same functional value. For example, take $w$ to be the Wittgenstein individual concept from 1889 to $1951, \mathrm{w}_{\mathrm{y}}$ the individual concept of the younger Wittgenstein defined from 1889 to 1921 , and $\mathrm{w}_{\mathrm{o}}$ the concept of the older Wittgenstein defined from 1922 to 1951, then $\mathrm{w}$ and $\mathrm{w}_{\mathrm{y}} \oplus \mathrm{w}_{\mathrm{o}}$ are different sum individuals, but have the same value.

For (37) we still have to define what it means that two individual concepts $\mathrm{x}, \mathrm{x}^{\prime}$ overlap at an index $i$; this is the case if there is an entity that is a part of $g(x)$ at $i$ and a part of $\mathrm{g}\left(\mathrm{x}^{\prime}\right)$ at $\mathrm{i}$, that is, if there is an $\mathrm{u}$ such that $\mathrm{u} \sqsubseteq \mathrm{g}(\mathrm{x})(\mathrm{i})$ and $\mathrm{u} \sqsubseteq \mathrm{g}\left(\mathrm{x}^{\prime}\right)(\mathrm{i})$.

The truth conditions of an example like (34), here simplified, can be rendered as follows:

$$
\begin{aligned}
& \llbracket \text { there are two outfits in the wardrobe } \rrbracket\left(\mathrm{i}_{0}\right)= \\
& \exists \mathrm{x}\left[\llbracket \text { outfit } * \rrbracket(\mathrm{i})(\mathrm{x})=2 \wedge \llbracket \text { in the } \text { wardrobe } \rrbracket\left(\mathrm{i}_{0}\right)(\mathrm{g}(\mathrm{x}))\right]
\end{aligned}
$$

The sentence is intuitively true under our assumption that the outfit $o_{1}$ made of $s_{1}$ and $\mathrm{p}_{1}$ and the outfit $\mathrm{o}_{4}$ made of $\mathrm{s}_{2}$ and $\mathrm{p}_{2}$ are in the wardrobe. According to (37)(a), it holds that $\llbracket$ outfit $* \rrbracket\left(\mathrm{i}_{0}\right)\left(\mathrm{o}_{1}\right)=1$ and $\llbracket$ outfit $* \rrbracket\left(\mathrm{i}_{0}\right)\left(\mathrm{o}_{4}\right)=1$, and as $\mathrm{o}_{1}$ and $\mathrm{o}_{2}$ do not overlap, we have $\llbracket$ outfit $* \rrbracket\left(\mathrm{i}_{0}\right)\left(\mathrm{o}_{1} \oplus \mathrm{o}_{2}\right)=2$. Even if the outfit $\mathrm{o}_{2}$, made of $\mathrm{s}_{1}$ and $\mathrm{p}_{2}$, and outfit $\mathrm{o}_{3}$, made of $\mathrm{s}_{2}$ and $\mathrm{p}_{1}$, are also in the wardrobe, they could not be counted because they overlap with $\mathrm{o}_{1}$ and $\mathrm{O}_{4}$. We of course could also sum up $\mathrm{o}_{2}$ and $\mathrm{o}_{3}$ instead, which would yield the same result.

It appears that sentences like There are four outfits in the wardrobe are felt to be ambiguous by some speakers, and can be considered true in one reading in which there are only two shirts and two pants in the wardrobe. This second reading can be generated by another construction of measure functions that differs from (37) by requiring that in the additivity clause, it is sufficient that $\mathrm{x} \neq \mathrm{x}^{\prime}$, that is, $\mathrm{x}$ and $\mathrm{x}^{\prime}$ may in fact overlap. Such weakened cases of additivity that allow for overlap are also relevant in cases like counting craters on the moon.

\subsection{Collective and Cumulative Interpretations}

Having sum individual concepts also enables the interpretation of collective interpretations as in the following case: 
(40) Two (of the) outfits are rather similar to each other.

This is a predication on a sum individual concept, which is true iff the atomic parts stay in a similarity relation to each other (the strong interpretation of reciprocals; for weaker interpretations see Dalrymple et al. (1998) and subsequent literature on the "strongest meaning hypothesis"). Here, $\leq \mathrm{a}$ is the atomic part relation on sum individual concepts.

$$
\begin{aligned}
& \exists \mathrm{x}\left[\llbracket \text { outfit } * \rrbracket\left(\mathrm{x}_{0}\right)(\mathrm{x})=2 \wedge \forall \mathrm{x}^{\prime} \forall \mathrm{x}^{\prime \prime}\left[\mathrm{x}^{\prime} \leq_{\mathrm{a}} \wedge \mathrm{x}^{\prime \prime} \leq_{\mathrm{a}} \mathrm{x} \wedge \mathrm{x}^{\prime} \neq \mathrm{x}^{\prime \prime}\right.\right. \\
& \left.\left.\rightarrow \llbracket \text { similar } \rrbracket\left(\mathrm{i}_{0}\right)\left(\mathrm{x}^{\prime}, \mathrm{x}^{\prime \prime}\right)\right]\right]
\end{aligned}
$$

The interpretation of expressions like two outfits proposed here is also possible for the non-collective examples we started out with, provided that we assume that verbal predicates, when applied to sets of individual concepts, distribute over their elements. Instead of (23) we can entertain the following analysis:

$$
\begin{aligned}
& \llbracket[\text { it is is possible to make four outfits with this }] \rrbracket\left(\mathrm{i}_{0}\right) \\
& =\exists \mathrm{x}\left[\llbracket \text { outfit } * \rrbracket\left(\mathrm{i}_{0}\right)(\mathrm{x})=4 \wedge \mathrm{x}=\mathrm{s}_{1} \bigoplus \mathrm{s}_{2} \bigoplus \mathrm{p}_{1} \bigoplus \mathrm{p}_{2} \wedge\right. \\
& \forall \forall \mathrm{x}^{\prime}\left[\mathrm{x}^{\prime} \leq \mathrm{a} x \rightarrow \exists \mathrm{i}^{\prime} \in \mathrm{R}\left(\mathrm{i}_{0}\right) \exists \mathrm{y} \exists \mathrm{i}^{\prime \prime}\left[\mathrm{i}^{\prime \prime} \angle \mathrm{i}^{\prime} \wedge \neg \mathrm{i}^{\prime \prime} \in \mathrm{DOM}\left(\mathrm{x}^{\prime}\right) \wedge\right.\right.
\end{aligned}
$$

[y causes in $\mathrm{i}^{\prime \prime}:\left[\mathrm{i}^{\prime} \in \operatorname{DOM}(\mathrm{x})\right]$ ]]]

This states that there are four outfits $\mathrm{x}$ that consist of the two shirts and two pants, and that it is possible for each atomic part $\mathrm{x}^{\prime}$ of $\mathrm{x}$ that some agent $\mathrm{y}$ brings it about to be realized.

Sum individual concepts are also relevant for cumulative interpretations (Scha 1981). Assume that a kindergarten owns a construction set with which all kinds of vehicles can be constructed, but only one at a time (there are only four wheels in the construction set).

(43) Dozens of children have built hundreds of vehicles with this construction set.

Such interpretations have been explained as a consequence of the cumulativity of verbal predicates (cf. Krifka 1989; Sternefeld 1998). That is, transitive predicates like build are interpreted such that if $\mathrm{x}$ builds $\mathrm{y}$ and $\mathrm{x}^{\prime}$ builds $\mathrm{y}^{\prime}$, then $\mathrm{x} \oplus \mathrm{x}^{\prime}$ builds $\mathrm{y} \oplus \mathrm{y}^{\prime}$. This interpretation is triggered by Sternefeld's operator $* *$, here adapted as in (43), where $\mathrm{R}$ stands for the verbal predicate, type $\mathrm{s}(\mathrm{se})(\mathrm{se}) \mathrm{t}$, and $\leq$ is the part relation for sum individual concepts.

$$
* * R=\lambda i \lambda x \lambda y\left[\forall x^{\prime} \leq x \exists y^{\prime} \leq y\left[R(i)\left(x^{\prime}\right)\left(y^{\prime}\right)\right] \wedge \forall y^{\prime} \leq y \exists x^{\prime} \leq x[R(i)(x)(y)]\right]
$$

This allows for the following representation of (42) at an index $\mathrm{i}_{0}$, where " $\gg 24$ " and " $\gg 200 "$ state that a number is in the range of dozens and hundreds, respectively. 
(45)

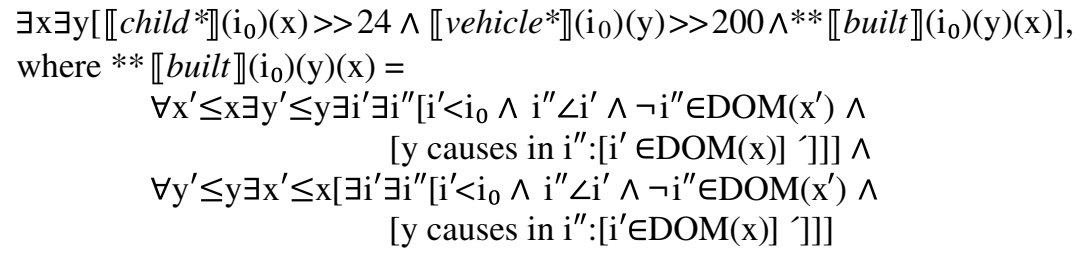

This states that there is a sum individual concept $\mathrm{x}$ that are dozens of children and a sum individual concept $y$ that are hundreds of vehicles, and that each part of the children built some part of the vehicles, and each part of the vehicles were built by some of the children. This renders the cumulative reading of (43) in an adequate way.

\section{The Property Analysis}

In this paper I have argued for individual concepts in our conceptual representation, and in particular, for the ability to count individual concepts. There is a proposal on a related topic, "Counting Concepts" by Condoravdi et al. (2001), which analyzes examples like the following in a way that looks similar to what we have proposed for configurations.

(46) The mayor prevented three strikes.

Prevent is analyzed as an intensional predicate, like seek, which Condoravdi et al. (2001) interpret, following Zimmermann (1992), as having a property argument:

$$
\begin{aligned}
& \llbracket \text { The mayor prevented a strike } \rrbracket\left(\mathrm{i}_{0}\right) \\
& =\exists \mathrm{i}<\mathrm{i}_{0}[\llbracket \text { prevent } \rrbracket(\mathrm{i})(\llbracket \text { strike } \rrbracket)(\llbracket \text { the mayor } \rrbracket)] \\
& =\exists \mathrm{i}<\mathrm{i}_{0}\left[\llbracket \text { prevent } \rrbracket(\mathrm{i})\left(\lambda \mathrm{i}^{\prime} \lambda \mathrm{u}\left[\mathrm{u} \text { is a strike in } \mathrm{i}^{\prime} \rrbracket\right)(\text { the mayor })\right]\right.
\end{aligned}
$$

This captures the reading in which no reference to a specific strike is intended. The object DP, a strike, denotes a property of entities.

There is also a specific reading: There was a threat for a strike that was about to form, and the mayor prevented that strike from happening. The normal solution for specific reading, giving the noun phrase wide scope (cf. (3)), does not work. It entails the existence of a strike $\mathrm{u}$-but this is exactly what the next conjunct says was prevented.

$$
\exists \mathrm{i}<\mathrm{i}_{0} \exists \mathrm{u}\left[\llbracket \text { strike } \rrbracket(\mathrm{i})(\mathrm{u}) \wedge \llbracket \text { prevent } \rrbracket(\mathrm{i})\left(\lambda \mathrm{i}^{\prime} \lambda \mathrm{v}[\mathrm{u}=\mathrm{v}]\right)(\text { the mayor })\right]
$$

Condoravdi et al. propose a solution for the specific interpretation using "subconcepts" (that is, subproperties). No strict definition is given, but we certainly should assume that a superconcept applies to all indices and individuals a subconcept applies 
to. The specific reading of the mayor prevented a strike can be given as follows, where $\subseteq_{\text {sc }}$ is the subconcept relation.

$$
\exists \mathrm{P}\left[\mathrm{P} \subseteq_{\mathrm{sc}} \llbracket \text { strike } \wedge \wedge \exists \mathrm{i}\left[\mathrm{i}<\mathrm{i}_{0} \wedge \llbracket \text { prevent } \rrbracket(\mathrm{i})(\mathrm{P})(\mathrm{m})\right]\right]
$$

For the interpretation of three strikes, Condoravdi et al. (2001) discuss various options, settling on a generalized quantifier analysis:

(50) 【the mayor prevented three strikes》 $\left(\mathrm{i}_{0}\right)$ $=\#\left(\lambda \mathrm{P}\left[\mathrm{P} \subseteq \subseteq_{\mathrm{sc}} \llbracket\right.\right.$ strike $\rrbracket \wedge \exists \mathrm{i}\left[\mathrm{i}<\mathrm{i}_{0} \wedge \llbracket\right.$ prevent $\rrbracket(\mathrm{i})(\mathrm{P})($ the mayor $\left.\left.)\right]\right) \geq 3$

But for this to work, the notion of subconcept must be properly restricted. One entity may fall under different subconcepts of strike, e.g. it might be a strike of the railroad workers and at the same time (as railroad workers are public workers) a strike of the public workers. Obviously, the subconcepts that we count should not be such that one is included in the other. Hence Condoravdi et al. propose to restrict counting to minimal subconcepts, that is, to "maximally specific instantiated concepts".

The use of minimal subconcepts suggests that we actually better work with individual concepts, because then we get minimality for free, as individual concepts can apply to maximally one entity. Hence it seems natural to propose the individual concept analysis to examples of this type as well. The natural reading of (45) is that what the mayor prevented was that three specific strike threats led each to a fullblown strike. In each world at which these strikes would have been realized, there would have been exactly one realization.

$$
\begin{aligned}
& \llbracket \text { the mayor prevented three strikes } \rrbracket\left(\mathrm{i}_{0}\right) \\
& \left.=\exists \mathrm{x}\left[\llbracket \text { strike } * \rrbracket\left(\mathrm{i}_{0}\right)(\mathrm{x})=3 \wedge \forall \mathrm{x}^{\prime} \leq \mathrm{a} \mathrm{x}^{\prime} \mathrm{i}^{\prime}<\mathrm{i}_{0} \text { [the mayor prevented } \mathrm{x}^{\prime} \text { at } \mathrm{i}^{\prime}\right]\right]
\end{aligned}
$$

This says that the three strikes consists of three individual concepts $\mathrm{x}$ that are strikes, and that for each $\mathrm{x}^{\prime}$ there exists an index $\mathrm{i}^{\prime}$ in the past of the actual time $\mathrm{i}_{0}$ such that the mayor prevented at $\mathrm{i}^{\prime}$ the strike $\mathrm{x}^{\prime}$ from happening. Where prevent denotes a rather involved concept; it means that the subject referent (here: the mayor) caused the object referent (here: $x^{\prime}$ ) not to be realized, which means in turn that, if the mayor would not have acted then $x^{\prime}$ would exist for all normal continuation of $i^{\prime}$.

But there is still an issue of identity to be considered: For example, assume that an announced strike is declared illegal, and the workers plan another strike with similar goals and methods to circumvent the court ruling, but this strike is declared illegal as well. In which sense can we say that two strikes were declared illegal? This depends on rather specific criteria. Formal semantics can only provide the general format of the objects of lexical semantics. 


\section{Conclusion}

In this paper I have discussed the meaning of sentences that contain reference to what I called "configurational" objects, as denoted by such terms as outfit or tangram figure, or even crane and word. Configurational objects consist of parts that can be reconfigured, and exist only at those indices in which they stand in the appropriate configuration. I have argued that configurational objects can fruitfully be analyzed as individual concepts, functions from indices to entities. I have developed ways how such concepts can be counted in count-noun constructions like four outfits. I then argued that more regular entities like shirts should also be represented by individual concepts, albeit with more stable temporal properties, and I have shown that there are contexts in which a configurational object like outfit can actually be coerced to the object it consists of.

The general direction of this paper points towards a theoretical framework in which the objects referred to in language, and consequently, the objects of our cognition, should be seen as individual concepts. The notion of an object contains the ability to identify the same object over different indices, and this is precisely achieved by individual concepts. Some objects are temporally convex in the sense that they have a continuous existence from an initial time to a final time (such as shirts and pants), others have a more spotted existence (such as outfits). There are various other examples of objects with apparently extraordinary identity criteria, such as waves. Whether this view is suitable, or even sustainable, cannot be answered in this short paper. At least I hope to have shown that it provides us with ways to give truth conditions to sentences that count configurational objects.

\section{References}

Barwise, J., \& Cooper, R. (1981). Generalized quantifiers and natural language. Linguistics and Philosophy, 4, 159-219.

Carlson, G. N. (1977). A unified analysis of the English bare plural. Linguistics and Philosophy, 1, 413-456.

Condoravdi, C., Crouch, R., \& van den Berg, M. (2001). Counting concepts. In R. van Rooij \& M. Stokhof (Eds.), Proceedings of the thirteenth Amsterdam colloquium (pp. 67-72).

Dalrymple, M., et al. (1998). Reciprocal expressions and the concept of reciprocity. Linguistics and Philosophy, 21, 159-210.

Grosu, A., \& Krifka, M. (2007). 'The gifted Mathematician that you claim to be': Equational intensional reconstruction relatives. Linguistics and Philosophy, 30, 445-485.

Gupta, A. (1980). The logic of common nouns: An investigation in quantified modal logic. New Haven: Yale University Press.

Heim, I., \& Kratzer, A. (1998). Semantics in generative grammar. London: Blackwell.

Krifka, M. (1989). Nominal reference, temporal constitution and quantification in event semantics. In R. Bartsch, J. van Benthem, \& P. van Emde Boas (Eds.), Semantics and contextual expressions (pp. 75-115). Dordrecht: Foris.

Krifka, M. (1990). Four thousand ships passed through the lock: Objectinduced measure functions on events. Linguistics and Philosophy, 13, 487-520. 
Krifka, M. (1995). Common nouns: A contrastive analysis of Chinese and English. In: G. N. Carlson \& F. J. Pelletier (Eds.), The generic book (pp. 398-411). Chicago, London: The University of Chicago Press.

Landman, F. (2016). Iceberg semantics for count nouns and mass nouns: Classifiers, measures and portions. Baltic International Yearbook of Cognition, Logic and Communication, 11.

Lewis, D. (1973). Causation. The Journal of Philosophy, 70, 556-567.

Link, G. (1983). The logical analysis of plurals and mass terms: A latticetheoretical approach. In R. Bäuerle, C. Schwarze, \& A. von Stechow (Eds.), Meaning, use and the interpretation of language (pp. 303-323). Berlin, New York: Walter de Gruyter.

Löbner, S. (2011). Concept types and determination. Journal of Semantics, 28, 279-333.

Montague, R. (1973). The proper treatment of quantification in ordinary English. In K. J. J. Hintikka, J. M. E. Moravcsik, \& P. Suppes (Eds.), Approaches to natural language (pp. 221-242). Reidel: Dordrecht.

Paul, M. (1994). Young Mozart and the Joking Woody Allen. Proper names, individuals and parts. In SALT IV (pp. 268-281). Cornell: CLC Publications.

Rothstein, S. (2010). Counting and the mass-count distinction. Journal of Semantics, 27, 343-397.

Scha, R. J. H. (1981). Distributive, collective, and cumulative quantification. In J. A. G. Groenendijk, T. M. V. Janssen, \& M. B. J. Stokhof (Eds.), Formal methods in the study of language (Vol. 135, pp. 483-512). Amsterdam: Mathematical Centre Tracts.

Sternefeld, W. (1998). Reciprocity and cumulative predication. Natural Language Semantics, 6 , 303-337.

von Stechow, A. (2001). Temporally opaque arguments in verbs of creation. In C. Cechetto, G. Chierchia, \& M.T. Guasti (Eds.), Semantic interfaces: Reference, anaphora, aspect (pp. 278-391). Stanford: CSLI Publications.

Zimmermann, T. E. (1992). On the proper treatment of opacity in certain verbs. Natural Language Semantics, 1, 149-180.

Open Access This chapter is licensed under the terms of the Creative Commons Attribution 4.0 International License (http://creativecommons.org/licenses/by/4.0/), which permits use, sharing, adaptation, distribution and reproduction in any medium or format, as long as you give appropriate credit to the original author(s) and the source, provide a link to the Creative Commons license and indicate if changes were made.

The images or other third party material in this chapter are included in the chapter's Creative Commons license, unless indicated otherwise in a credit line to the material. If material is not included in the chapter's Creative Commons license and your intended use is not permitted by statutory regulation or exceeds the permitted use, you will need to obtain permission directly from the copyright holder.

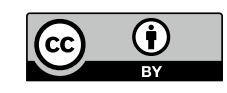

